\title{
Shock induced polymorphic transition in quartz, carbon, and boron nitride
}

\author{
Hua Tana) and Thomas J. Ahrens \\ Seismological Laboratory, California Institute of Technology, Pasadenc, Californie 91125
}

(Received 8 May 1989; accepted for publication 31 July 1989)

\begin{abstract}
A theory describing the polymorphism induced by shock waves in silicates, oxides, sulfies, and many inorganic solids is presented. Shock wave experiments conducted on these and other materials indicate that many transformations to high-pressure phases are triggered via the production of shear bands and, in some cases, formation of high-density amorphous phases. Shock states in the mixed phase regimes, of quartz, carbon, and boron nitride, are quantitatively described in terms of the properties of both their low-and high-pressure phases. Good agreement between the calculated results and measured Hugoniot data in the mixed phase tegime is obtained. By fitting the pressures of the onset of the phase transition from graphite to diamond, and associating its triggering with crossing the extension of the metastable melting line of graphite, we obtain a similar shaped curve to the metastable melting line obtained by Bundy [1. Geophys. Res. 85, 6930 (1980)]. Similarly, the transition from quartz to stishovite is associated with the metastable melting line of coesite. The present theory, when fit to the onset of the mixed phase regime of graphitelike boron nitride transforming to cubic boron nitride Hugoniot, predicts the standard entropy for cubic BN to be $0.4-0.5 \mathrm{~J} / \mathrm{g} \mathrm{K}$.
\end{abstract}

\section{ก. MTRODUGHON}

Polymorphic phase transition induced by shock waves have been observed in several condensed materials. In several cases, e.g., porous quartz, ${ }^{1}$ carbon, $^{2}$ and boron nitride, ${ }^{3}$ large fractions of high-pressure phase are retained upon unloading, leaving litle doubt that phase transition to a highpressure crystalline phase occurs.

Shock induced polymorphism in crystal and fused quartz was first studied by Wackerle, ${ }^{1}$ and subsequently McQueen pointed out that stishovite is the high-pressure phase induced upon compression of initially $\alpha$ and fused quartz. The Hugoniot curve of pressed graphite demonstrates transformation into a high-pressure phase (diamond) starting at $\sim 20 \mathrm{GPa}$. Above $-50 \mathrm{GPa}$, it appears that pressed graphite is totally converted into diamond. The same phenomena are observed in graphite-structural boron nitride $(g-\mathrm{BN})$ which undergoes an increasing amount of phase transformation to a diamondlike boron nitride ( $c$ BN) phase between shock pressures of $\sim 12-20 \mathrm{GPa}$. Previously little effort has been expended in describing the thermodynamic behavior where materials appear to be in a mixed-phase regine, that is, where partial polymorphic phase transitions occur. ${ }^{5}$ Ahrens ${ }^{6}$ recently proposed a model to explain the mechanisms of the polymorphism in silicates. In the present paper, we are revising this theory and apply it to the quartz/stishovite, graphite/diamond, and $\mathrm{g} \cdot \mathrm{BN} / \mathrm{c}^{-}$ BN phase transformations.

\section{THEORY AND METHOD}

Shock wave data for oxides, sulfides, and silicates demonstrate similar shaped Hugoniot curves as shown in Fig. I; the low-pressure phase regime ( $\alpha$ quartz) which has the structure of the starting material, the high-pressure phase

\footnotetext{
a) Permanent address: Beijing Institute of Technology, P.O. Box 327,
} Beijing, People's Republic of China. regime (stishowite) which is an allotrope of the low-pressure phase, and the mixed phase regime where the two phases coexist. Four separate observations suggest that shock-induced phase changes in these materials occur via crystallization within narrow zones of shock-deformation-induced motten material called sheat bands, and not the solid state. These observations include:

(1) Recen pyrospectrometric measurements of shear band temperatures in $\mathrm{NaCl}, \mathrm{SiO}_{2}$, and $\mathrm{CaAl}_{2} \mathrm{Si}_{2} \mathrm{O}_{8}$., The shear band temperatures are consistent with the concept that narrow zones representing shear-heated material are buffered by the high-temperature meling point of the highpressure phase which is produced in the mixed phase region. These shear bands, which typically represent $10^{-3}$ $10^{-2}$ mass fraction of the material undergoing transformation, are sketched in Fig. 2 .

(2) In the range of $0-40 \mathrm{GPa}$, melts and glasses of silicates continuously and reversibly approach, via $\mathrm{Si}-\mathrm{O}-\mathrm{Si}$

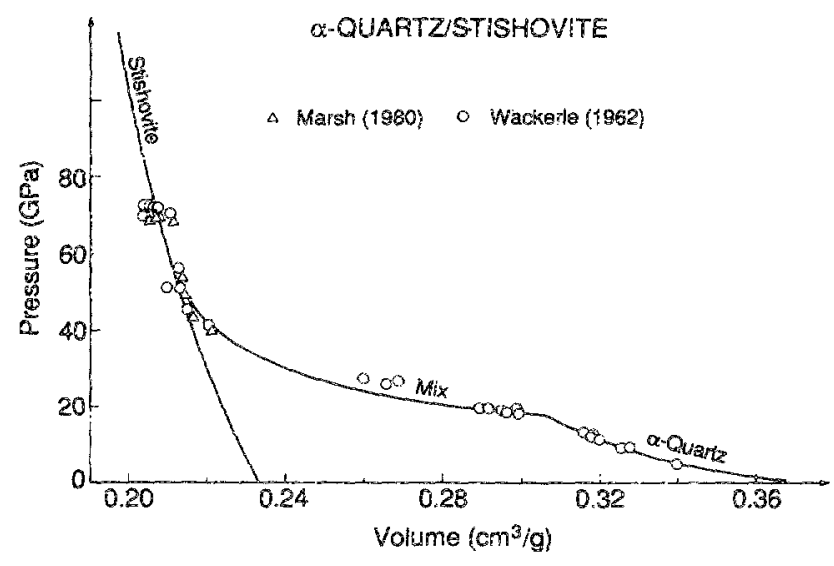

FIG. 1. Calculated and observed $\alpha$-guartz to stishovite transformation showing low-pressure, mixed-phase, and high-pressure regime. 


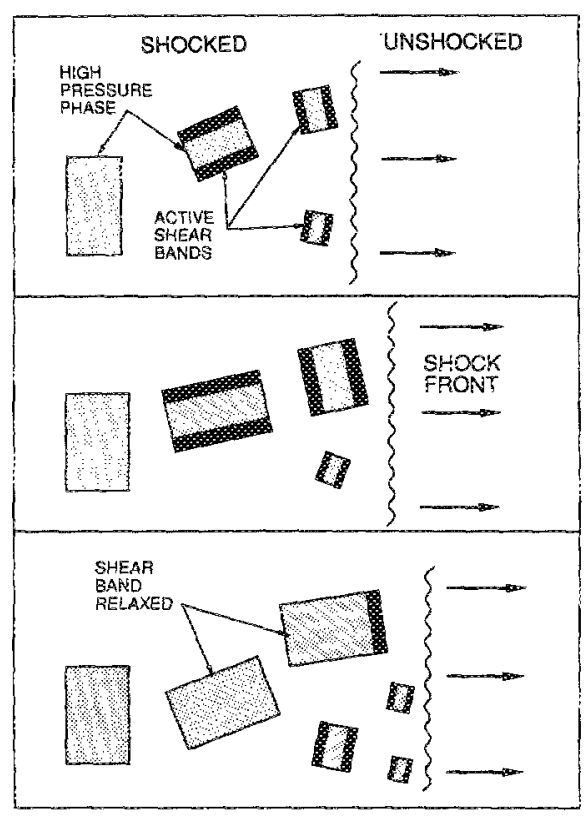

FIG. 2. Production of high-pressure phase via shear bands. High-pressure phase grows from hot sitear band zones which are activated behind propagating shock.

bond bending, the density and coordination of the closepacked oxides. ${ }^{10,12}$ This process is shown in Fig. 3 for $\mathrm{SiO}_{2}$. It is proposed that bond bending occurs in two of the zones of Fig. 2: the compressed, but not shear-heated, material, and within the shear heated material. it probably occurs most efficiently in the shear-heated material.

(3) Transitions from crystals to a dense amorphous state can occur upon driving a solid across the negative sloping metastable extension of a fusion curve, as in the case of $\mathrm{H}_{2} \mathrm{O}$ (Ref. 13) (Fig. 4) and observed more recently in $\mathrm{SiO}_{2}$ (Refs. 14 and 15) (Fig. 5). It appears likely that the bond bending model of Fig. 3 gives rise to large scale transformation of fourfold to sixfold coordinated silicates upon passing through an amorphous state. Transformation of graphite to diamond requires compression along the $c$ axis of graphite and bond bending within the sheet of $C$ hexagons of the initial graphite structure. ${ }^{16}$

(4) The sound velocities of silicates shocked to states in the mixed regime immediately unload with a rarefaction velocity corresponding to the bulk sound speed rather than the longitudinal elastic velocity. This demonstrates that shocked silicates lose their strength, ${ }^{17}$ probabiy as a resuit of the melted material produced in the ubiquitous shear bands or planar features which we associate with the planar features found in recovered shocked silicates.

\section{A. Mechanism of shock-induced polymorphic phase transformation}

A key assumption of the proposed model is that transformation to a high-density amorphous or possibly liquid phase which rapidly crystallized to the high-pressure phase is triggered by the high temperatures in the shear band and upon crossing the metastable extension of a melting curve, which is coesite in the case of $\mathrm{SiO}_{2}$ and graphite phase in the

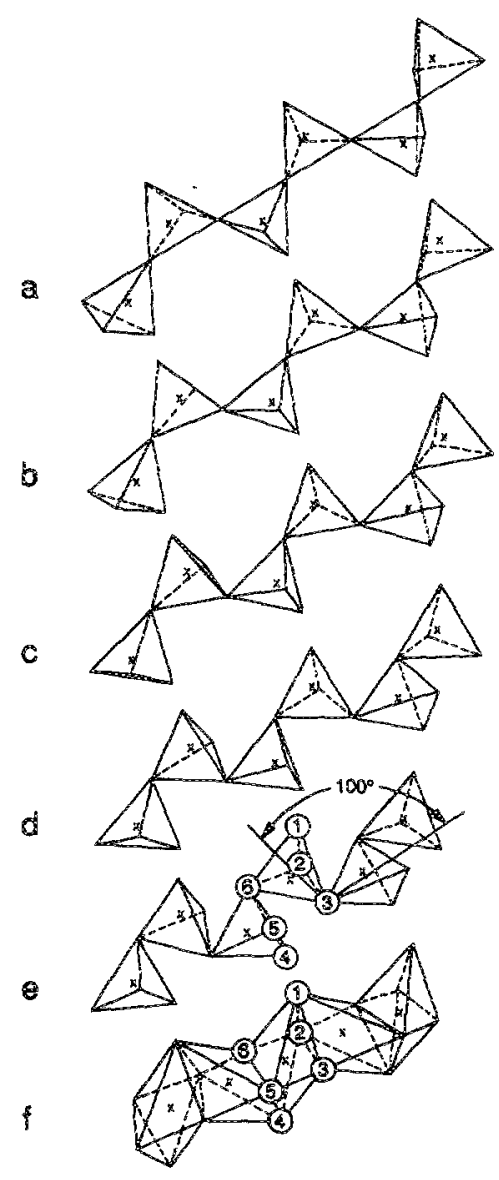

FIG. 3. Amorphous material in the high-pressure region gradually transforms from fourfold to sixfold coordination. Here sketched is progressive distortion of a chain of $\mathrm{SiO}_{4}$ tetrahedra. Dahhed lines are "hidden" edges of polyhecira. (a) $\mathrm{Si}-\mathrm{O}-\mathrm{Si}$ angle $=180^{\circ}$. (b) $\mathrm{Si}-\mathrm{O}-\mathrm{Si}$ angle $=16 \mathrm{C}^{\circ}$. (c) $\mathrm{Si}-\mathrm{O}-\mathrm{Si}$ angle $=140^{\circ}$. (d) $\mathrm{Si}-\mathrm{O}-\mathrm{Si}$ angle $=120^{\circ}$. (e) $\mathrm{Si}-\mathrm{O}-\mathrm{Si}$ an gle $=100^{\circ}$. (f) Same as chain in (e), except coordination polyhedra redrawn a chain of face-shared octahedra. The numbered circles show the positions of the same oxygen atoms in (e) and (f). Si positions (crosses) have been moved to be near the centers of the octahedra in $(f)$. Because of the finite length of the chain in (e), one Si and one $O$ (at lower left) are not reproduced in (f) (after Stolper and Ahrens, 1987).

case of carbon and boron nitride (Fig. 2). A consequence of this assumption and the present shock temperature calculations is that the onset of the transition oceurs at a lower shock pressure in fused quartz than crystal quartz. Moreover, the metastable melting curve shown goes through the pressures of the onset of transformation in $\alpha$ quartz and fused quartz, as well as the pressure range where Hemley ${ }^{14}$ and Hemley et $a l{ }^{15}$ observe amorphization of quartz and coesite. Recently, crystal anorthite $\left(\mathrm{CaAl}_{2} \mathrm{Si}_{2} \mathrm{O}_{8}\right)^{34}$ has also been observed to transform to a glass at $300 \mathrm{~K}$ and high pressure and we infer that this also arose because the metastable extension of the post-stishovite + kynite + garnet phase fusion is intecept$\mathrm{ed}^{35}$ (Fig. 5). The present model also predicts lower phase transformation pressures to stishovite in porous quartz than crystal quartz. ${ }^{21}$ We assume that once a shear band forms, transformation from fourfold to sixfold transformation occurs, in part, via the Si-O-Si bond bending model of Stolper and Ahrens ${ }^{10}$ in the solid and amorphous state. The onset of this transition mechanism is suggested to be analogous to the transformation of ice- $I_{h}$ to dense amorphous 


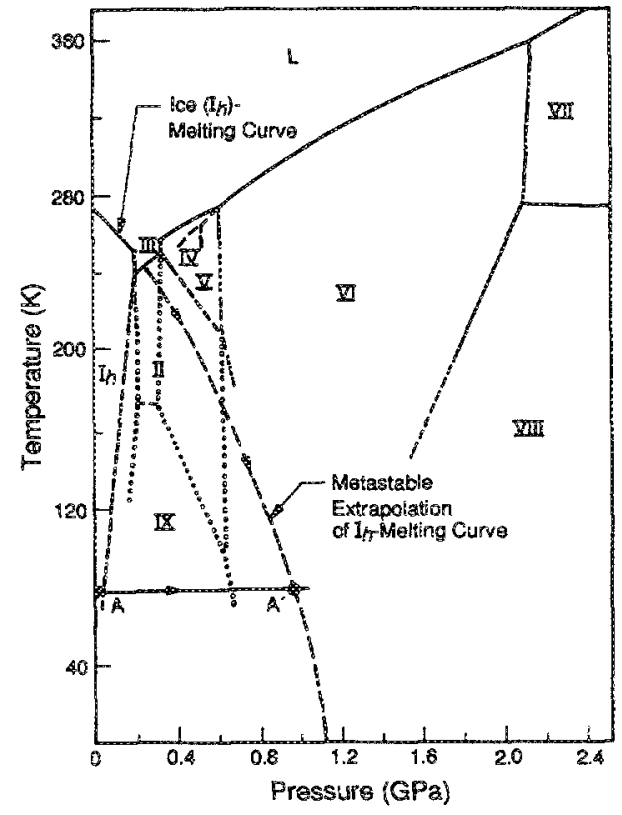

FIG. 4. Phase diagram of $\mathrm{H}_{2}$ O. Upon sudden pressurization from state $A$ to $A^{\prime}$, amorphous water is produced metastably in stabilicy field of ice $V I$. Transformation occurs upon crossing metastable extension of ice $I_{h}$ melting curve projected into the stability field of ice $V I$ (after Mishima et al. 1984).

$\mathrm{H}_{2} \mathrm{O}$-ice upon compression at $77 \mathrm{~K}$ along a path intersecting the extrapolation of the ice- $l_{h}$ melting curve into the ice- IV field $^{13}$ (as shown by line A-A' of Fig. 4). Upon compressing the low-pressure phase ice, $I_{h}$, at $77 \mathrm{~K}$ through the stability field of ice $I X$ (along the line A-A' of Fig. 4) and intersection with the extrapolation of the $I_{n}$ meiting curve, the high density, $1.31 \mathrm{~g} / \mathrm{cm}^{3}$, amorphous phase of ice is formed within the stability of ice-VI. Upon release of pressure, the density of the amorphous phase remains anomalously high $(1.17 \mathrm{~g} /$

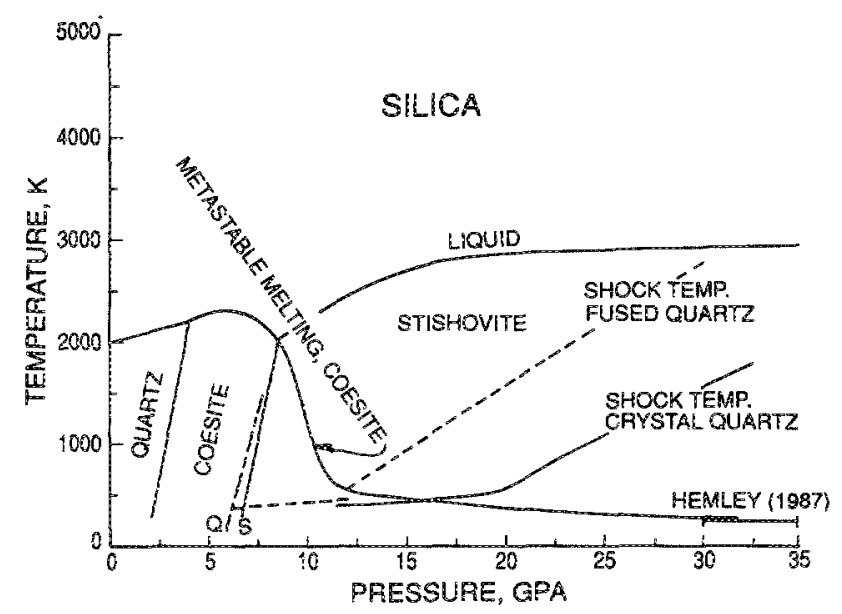

FIG. 5. Proposed pressure-temperature phase diagram of $\mathrm{SiO}_{2}$. Upon $\mathrm{Hu}$ goniot of crystal quartz crossing metastable melting curve of coesite, at $\sim 20$ GPa, transformation to glass and then stishovite occurs. Similar transformation of shocked fused quartz is predicted to occur at higher temperature and pressure of $\sim 13 \mathrm{GPa}$. At room temperature, both coesite and crystal quartz become amomphous at static pressures of $30-35 \mathrm{GPa}$ (after Schmit and Ahrens, 1989). Direct transition between quartz and stishovite indicated line labeled $Q / \$$. $\mathrm{cm}^{3}$ ). This compares to a density, $0.93 \mathrm{~g} / \mathrm{cm}^{3}$, for ice- $I_{h}$. This appears to be analogous to the formation of both static pressure and shock-induced glass in silicates. These glasses have appreciably higher densities than the normal silicate glasses and we infer that, after formation of the amorphous phase, crystallization to the high-pressure phase in shear bands could occur rapidly.

Another issue that needs to be addressed is the role of the hot shear bands in the energetics of the phase transition. We assume that the shear banding results from the localized release of elastic strain energy reflecting the finite strength of the material. ${ }^{8}$ The maximum shear strain energy is assumed to be some fraction of that which may be released upon shock compression to the Hugoniot elastic limit state. The maximum shear scress (associated with one-dimensional compression to the Hugoniot elastic limit stress $\sigma_{1}$ ) is

$$
\tau_{m}=(1-2 v) \sigma_{1} /\left[(1-v)^{2}\right],
$$

where $v$ is Poisson's ratio. Taking the average value of the $\sigma_{1}$ to be $\sim 6 \mathrm{GPa}^{1}$ and the value of $v$ as 0.077 , the specinc energy available for shear bands $E_{\mathrm{sb}}$ is

$$
E_{\mathrm{sb}}=f \tau_{m}^{2} /(2 \mu)
$$

where $\mu$ is the shear modulus. Using a value of $\mu=7.7 \mathrm{GPa}$ and an assumed value of $f=0.5$, we find that $E_{\mathrm{s} b}=0.25 \mathrm{~kJ} /$ g. If this value is compared to $E_{\text {tot }}$, the sum of the energy density required to transform to stishovite, $0.8 \mathrm{~kJ} / \mathrm{g}$, and to bring stishovite to the melting point $\sim 3000 \mathrm{~K}$, ${ }^{7}$ and the latent heat of melting $2.4 \mathrm{~kJ} / \mathrm{g}^{22}$ a total of $6.9 \mathrm{~kJ} / \mathrm{g}$ is required to obtain moiten stishovite. Thus, we might expect that the mass fraction of material involved in shear bands to be $E_{\mathrm{sb}} / E_{\text {tot }}=0.046$. This value is comparable to the fraction of material observed to be emiting light in radiative experiments. ${ }^{7}$

Based on the above observations, we suggest that the triggering mechanism for transformation is assumed to be both shear bands depicted in Fig. 2 and formation of an amorphous phase as sketched in Fig. 4. The mixed-phase regime is described in terms of a transition to a dense highpressure phase. We infer that on a very short time scale $\left(\sim 10^{-8} \mathrm{~s}\right)$, the molten material in shear bands in tum recrystallizes into the high-pressure phase. We also propose that shock-induced reconstructive transformations also occur via a molten state presented in shear bands.

However, it appears that not all the material that transforms to a dense molten and/or amorphous state transforms to a high-pressure phase. In some cases, the material remains amorphous even upon pressure release. Amorphous phases induced by shock pressures in excess of $35 \mathrm{GPa}$ were first recognized in laboratory experiments on quart $z^{18}$ and in plagioclase. ${ }^{19}$ Planar features which contain glass are observed both in nature and from laboratory shock recovery experiments in which silicates were driven into the mixed phase region. ${ }^{20}$ This glass often has a higher than normal index of refraction.

\section{B. Basic aquations}

The above transition mechanisms suggest that, although the low-pressure and high-pressure phases coexist in the mixed-phase regime, their shock states do not, in general, 
lie along the equilibrium phase lines. However, we assume that the two phases are intimately mixed after the shear bands come to thermal equilibrium and thus the high-and low-pressure phases are at the same temperature and pressure. The intemal energy of the starting material is assumed to be at zero energy, the shock pressure $P$ and energy, $E_{H}$ are related with each other via Hugoniot energy equation

$$
P=2 E_{H} /\left(V_{00}-V\right) \text {, }
$$

where $V_{00}$ is the initial volume of the material being shocked, $V$ is the total volume:

$$
V=\chi V_{1}+(1-\chi)_{2}
$$

$\chi$ is the mass fraction of the low-pressure phase in the mixedphase regime; subscripts 1 and 2 denote the low-pressure phase and high-pressure phase, respectively.

For simpicity we assume a Murnaghan isentrope and that the Grimeisen equation of state is valid in the mixedphase regime. The internal energies, $E_{1}$ and $E_{2}$, for each component phase will be

$$
\begin{aligned}
& E_{1}=E_{S_{1}}\left(V_{1}\right)+\left[P-P_{S 1}\left(V_{1}\right)\right] V_{1} / \gamma_{1}, \\
& E_{2}=E_{S_{2}}\left(V_{2}\right)+\left[P-P_{S 2}\left(V_{2}\right)\right] V_{2} / \gamma_{2}+E_{25},
\end{aligned}
$$

where $E_{S 1}$ and $E_{S 2}$ are the isentropic energies and $\gamma_{1}$ and $\gamma_{2}$ are the Grüneisen ratios. The Murnaghan isentrope takes a form

$$
P_{s}=\left(C_{0}^{2} / V_{0} n\right)\left[\left(V_{0} / V\right)^{n}-1\right]
$$

and

$$
E_{S}=-\int_{V_{0}}^{V} P_{S} d V .
$$

Here $C_{0}$ is the isentropic sound velocity, $V_{0}$ is the crystal volume, $E_{t r}$ is the phase transition energy, at standard conditions, and $n$ is a parameter specifying the zero pressure isentropic pressure derivative of the isentropic bulk modulars, $K_{s}: n=\left.\left(d K_{s} / d P_{s}\right)\right|_{p=0}$.

The temperature $T_{1}$ and $T_{2}$ of each component phase can be determined through the Debye specific heat, $C_{v}$ (Ref. 23):

$$
\begin{aligned}
& T_{1}=T_{S 1}+\left(E_{1}-E_{S 1}\right) / \bar{C}_{V 1} \\
& T_{2}=T_{S 2}+\left(E_{2}-E_{S 2}-E_{\mathrm{tr}}\right) / \bar{C}_{V 2} .
\end{aligned}
$$

Here $\bar{C}_{V}$ represents the average value of $C_{V}$ between tem- perature $T_{S}$ and $T$, of each component phase, while $T_{S 1}$ and $T_{S 2}$ are temperatures along the isentropes:

$$
\begin{aligned}
& T_{S 1}=T_{0} \exp \left[-\int_{V_{11}}^{V_{1}}\left(\frac{\gamma}{V}\right) d V\right], \\
& T_{S 2}=T_{0} \exp \left[-\int_{V_{i 2}}^{V_{2}}\left(\frac{\gamma}{V}\right) d V\right] .
\end{aligned}
$$

Here $T_{0}$ is initial temperature. The entropy for each component phase is

$$
\begin{aligned}
& S_{1}=S_{01}+\bar{C}_{V_{1}} \ln \left(T_{1} / T_{S_{1}}\right) \\
& S_{2}=S_{02}+\bar{C}_{V_{2}} \ln \left(T_{2} / T_{S_{2}}\right)
\end{aligned}
$$

The total entropy of the system is

$$
S=\chi S_{1}+(1-\chi) S_{2}
$$

Here $S_{01}$ and $S_{02}$ are standard entropies for low- and high-pressure phases, respectively.

Equations (3)-(13) express the pressure, volume, temperature, and entropy as functions of $\chi, V_{1}$ and $V_{2}$. These three unknowns are related by the energy equation

$$
E_{H}=\chi E_{1}+(1-\chi) E_{2}
$$

the temperature equation,

\begin{tabular}{|c|c|c|c|c|c|c|c|}
\hline Phase & $\begin{array}{c}\text { Transition starting } \\
\text { pressure } \\
\text { (GPa) }\end{array}$ & $\begin{array}{c}\text { Density } \\
\rho_{0} \\
\left(\mathrm{~g} / \mathrm{cm}^{3}\right)\end{array}$ & $\begin{array}{c}\text { Bulk sound } \\
\text { velocity } C_{0} \\
(\mathrm{~km} / \mathrm{s})\end{array}$ & $n$ & $\begin{array}{c}\text { Grüneisen tatio } \\
\gamma_{0}\end{array}$ & $\begin{array}{c}\text { Entropy } \\
S_{0} \\
(\mathrm{~J} / \mathrm{g} \mathrm{K})\end{array}$ & $\begin{array}{c}\text { Enthalpy } \\
H_{0} \\
(\mathrm{~kJ} / \mathrm{g})\end{array}$ \\
\hline$\alpha$ quartz & 18 & $2.648^{2}$ & $3.27^{\mathrm{b}}$ & $7.0^{\mathrm{c}}$ & $0.7^{4}$ & $0.69^{a}$ & 0.0 \\
\hline fused quartz & 11 & $2.204^{a}$ & $4.3^{c}$ & $4.5^{\circ}$ & $0.84^{\mathrm{e}}$ & $0.78^{\mathrm{a}}$ & $0.13^{\mathrm{a}}$ \\
\hline stishovite & & $4.287^{a}$ & $8.45^{f}$ & $3.4^{f}$ & $0.9^{g}$ & $0.462^{a}$ & $0.821^{2}$ \\
\hline
\end{tabular}

$$
T_{1}=T_{2} \text {, }
$$

or

$$
T_{S 1}+\left(E_{1}-E_{S 1}\right) / C_{V 1}=T_{S 2}+\left(E_{2}-E_{S 2}-E_{t}\right) / C_{V 2}
$$

and finaliy, the second law

$$
\int_{\infty}^{H} T d S=E_{H}+\int_{\infty}^{H} P d V .
$$

In Eq. (16), we define $T=\left(T_{1}+T_{2}\right) / 2$, and $\int_{00}^{H}$ denotes that this integration is calculated from the starting state 00 to the final shock state $H$ along an arbitrary path. Once we define a fixed value for $E_{n}$, Egs. (14)-(16) are solved to find the mass fraction $\chi$, the volume $V_{1}$ and $V_{2}$ and consequently,

TABLE I. Parameters for quartz-to-stishovite transformation.

${ }^{a}$ Robie et al. (see Ref. 29).

'Zamyshiyaev et al. (see Ref. 5).

'Fit to shock wave data in low-pressure phase regime.

“Anderson et al. (see Ref. 30).

In reference of $\alpha$-quartz data.

Fit to high-pressure data in high-pressure phase regime.

${ }^{8}$ For $\alpha$ quart $z$ to stishovite transformation, $\gamma_{0}=1.0$ is used for better fitting. 
TABLE II. Parameters for carbon-to-diamond transformation.

\begin{tabular}{|c|c|c|c|c|c|c|c|}
\hline Phase & $\begin{array}{c}\text { Transition starting } \\
\text { pressure } \\
\text { (OPa) }\end{array}$ & $\begin{array}{c}\text { Density } \\
\rho_{0} \\
\left(\mathrm{~g} / \mathrm{cm}^{3}\right)\end{array}$ & $\begin{array}{l}\text { Bulk sound } \\
\text { velocity } C_{0} \\
(\mathrm{~km} / \mathrm{s})\end{array}$ & $n$ & $\begin{array}{c}\text { Grüneisen ratio } \\
\gamma_{0}\end{array}$ & $\begin{array}{c}\text { Entropy } \\
S_{0} \\
(J / g K)\end{array}$ & $\begin{array}{c}\text { Enthalpy } \\
H_{0} \\
(\mathrm{~kJ} / \mathrm{g})\end{array}$ \\
\hline $\begin{array}{l}\text { Pressed } \\
\text { Graphite }\end{array}$ & 23 & 2.28 & $4.5^{\mathrm{a}}$ & $5.0^{\mathrm{b}}$ & $0.724^{6}$ & $0.474^{\circ}$ & 0.0 \\
\hline ATJ graphite & 21 & 2.28 & $4.43^{2}$ & 5.0 & 0.724 & 0.474 & 0.0 \\
\hline Pyrolytic graphite & 42 & $2.21^{\mathrm{b}}$ & $4.75^{b}$ & $4.7^{\mathrm{a}}$ & $0.75^{\mathrm{b}}$ & 0.474 & 0.0 \\
\hline Diamond & & $3.51^{\mathrm{d}}$ & $12.16^{\mathrm{d}}$ & $3.0^{d}$ & $0.9^{4}$ & $0.198^{c}$ & $0.158^{\circ}$ \\
\hline
\end{tabular}

${ }^{2}$ Fit to Marsh's (see Ref. 25) shock wave data in low-pressure phase regime.

${ }^{b}$ R. G. McQueen and S. P. Marsh (see Ref. 2).

R. A. Robie et al. (see Ref. 29).

dM. N. Pavlovskii (see Ref. 27).

J. A. Dean (see Ref. 31 ).

TABLE III. Parameters for $g-B N$ to $c-B N$ transtormation.

\begin{tabular}{|c|c|c|c|c|c|c|c|}
\hline Phase & $\begin{array}{c}\text { Transition starting } \\
\text { pressure } \\
\text { (GPa) }\end{array}$ & $\begin{array}{c}\text { Density } \\
\beta_{0} \\
\left(\mathrm{~g} / \mathrm{cm}^{3}\right)\end{array}$ & $\begin{array}{c}\text { Bulk sound } \\
\text { velocity } C_{0} \\
(\mathrm{~km} / \mathrm{s})\end{array}$ & $n$ & $\begin{array}{c}\text { Grüneisen ratio } \\
\gamma_{0}\end{array}$ & $\begin{array}{c}\text { Entropy } \\
S_{0} \\
(J / g K)\end{array}$ & $\begin{array}{c}\text { Enthalpy } \\
H_{0} \\
(\mathrm{EJ} / \mathrm{g})\end{array}$ \\
\hline $\begin{array}{l}g-\mathbb{B N} \\
c-\mathbb{B N}\end{array}$ & 12 & $\begin{array}{l}2.29 \\
3.487\end{array}$ & $\begin{array}{l}4.2^{\mathrm{a}} \\
10.287^{\mathrm{d}}\end{array}$ & $\begin{array}{l}3.8^{a} \\
4.0^{d}\end{array}$ & $\begin{array}{c}0.9^{b} \\
0.6^{f}, 0.9^{f}\end{array}$ & $\begin{array}{l}0.596^{\circ} \\
0.48^{\circ}\end{array}$ & $\begin{array}{l}0.0 \\
0.0764^{\mathrm{e}}\end{array}$ \\
\hline
\end{tabular}

"Fit to Marsh's (see Ref. 25) shock wave data in low-pressure phase regime.

In reference to graphite.

'M. W. Chase er al. (see Ref. 32).

'E. Knittie et al. (see Ref. 28).

EH. Tan and T. J. Ahrens (see Ref. 33).

'See text.

all the thermodynamic quantities in the mixed-phase region, via the Newton-Raphson method.

\section{Numerical solution}

The Newton-Raphson method ${ }^{24}$ is used to solve Eqs. (14)-(16). We first transform Eq. (16) to a form that can be used in the iterative solution.

Consider a fixed energy $E_{f}$. Corresponding to this ener-

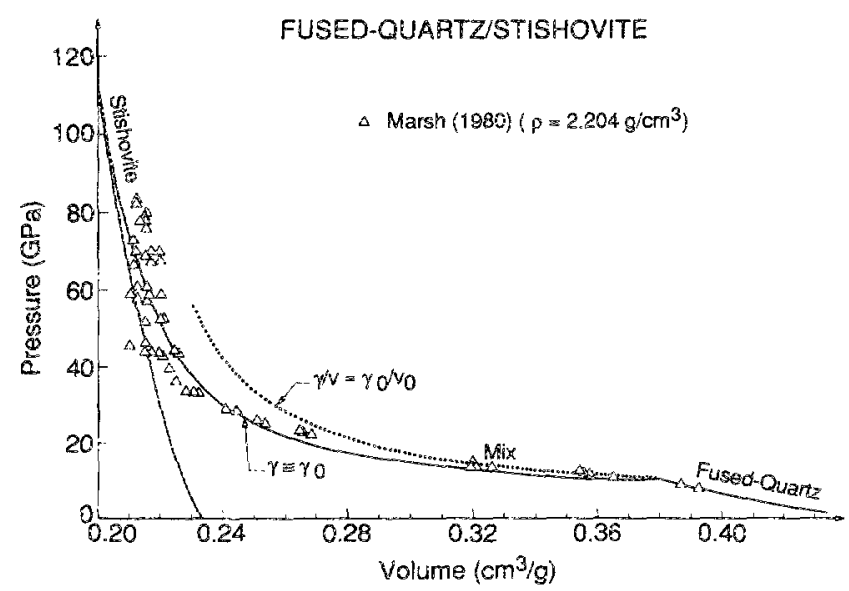

FIG. 6. Fused quartz to stishovite transition. Solid line in the mixed phase region is calculated using models $\gamma / V \equiv$ 至const, while the dotted line corresponding to $\gamma \equiv \gamma_{0}$. gy we calculate iteratively a series of states from the starting values of $\chi, V_{1}$, and $V_{2}$. If $(i-1)$ and $i$ are two such successive states belonging to this series, we may write

$$
\begin{aligned}
& \int_{00}^{i-1} T d S=E_{H}+\int_{\infty}^{i-1} P d V, \\
& \int_{\infty}^{i} T d S=E_{H}+\int_{\infty}^{i} P d V,
\end{aligned}
$$

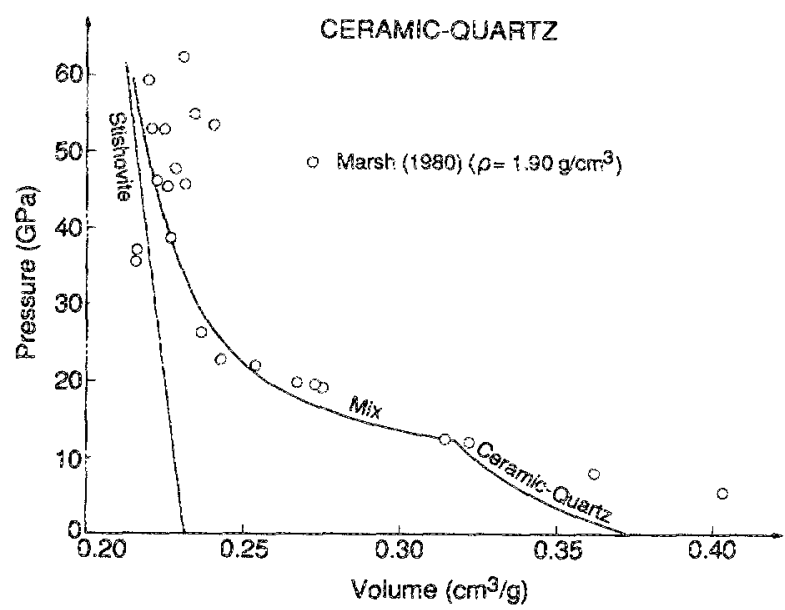

FIG. 7. Calculated results for ceramic quartz. Parameters used in the calculations are the same as usec for $\alpha$-quartz except that the Grineisen $\gamma$ for high-pressure phase is assumed to be 0.65 . 
or, upon subtracting Eq. (16a) from Eq. (16b)

$$
\int_{i-1}^{i} T d S=\int_{i=1}^{i} P d V \quad\left(E_{H}=\text { fixed value }\right)
$$

Equation (16c) defines a constraint to all the possible states corresponding to the fixed energy $E_{H}$. Since state $i$ is calculated iteratively using state $(i-1)$, which was the previous calculated or guessed value, we may write $\mathrm{Eq}$. (16c) as

$$
T \delta S=P \delta V
$$

or

$$
\begin{aligned}
& T\left[\left(S_{1}-S_{2}\right) \delta \chi+\chi\left(\delta S_{1}-\delta S_{2}\right)\right] \\
& \quad=P\left[\left(V_{1}-V_{2}\right) \delta \chi+\chi\left(\delta V_{1}-\delta V_{2}\right)\right]
\end{aligned}
$$

where

$$
\begin{aligned}
& \delta \chi=\chi^{(i)}-\chi^{(i-1)} \\
& \delta V_{1}=V_{1}^{(i)}-V^{(i-1)} \\
& \delta V_{2}=V_{2}^{(i)}-V_{2}^{(i-1)} \\
& \delta S_{1}=S_{1}^{(i)}-S_{i}^{(i-1)}
\end{aligned}
$$
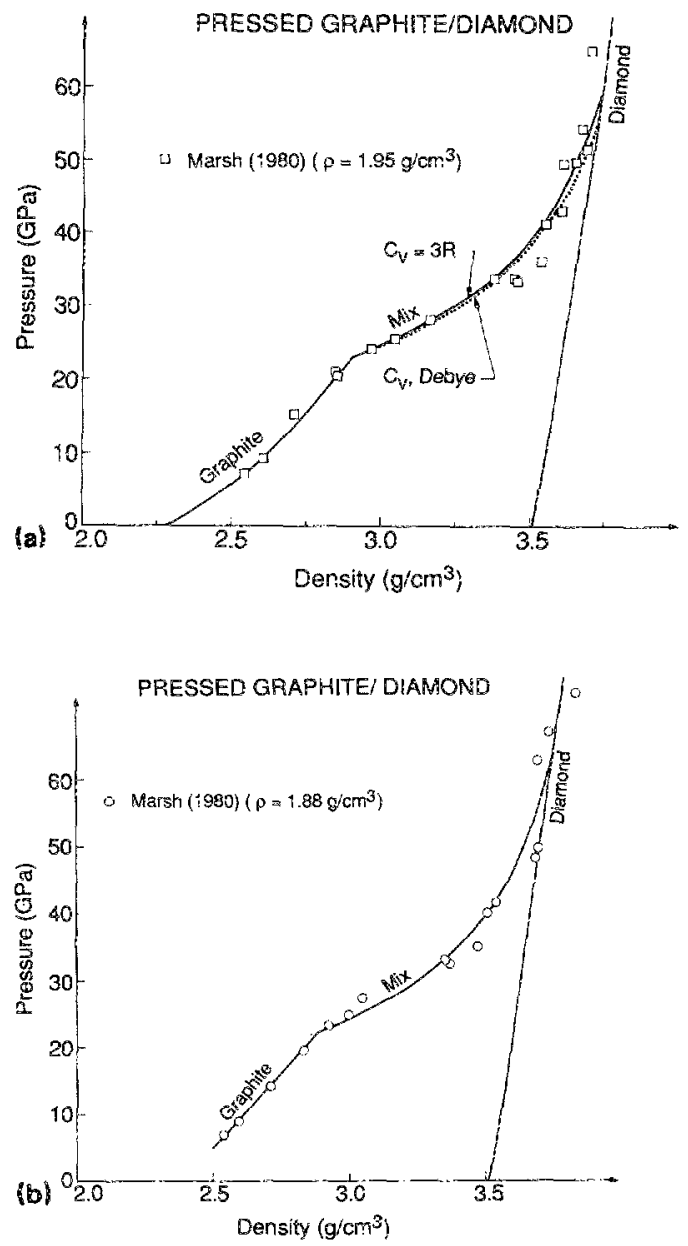

$$
\begin{aligned}
& \delta S_{2}=S_{2}^{(i)}-S_{2}^{(i-1)}, \\
& \delta S=S^{(i)}-S^{(i-1)}, \\
& \delta V=V^{(i)}-V^{(i-1)},
\end{aligned}
$$

here $\chi^{(i)}$ denotes the value of $\chi$ at state $i$, and so on. Equation (17) is used in the Newton-Raphson method instead of Eq. (16).

\section{APPLICATIONS FOR OUARTZ, CARBON, AND BORON NITRDE}

The equation of state of $\alpha$ quartz, fused quartz, and ceramic quartz, pressed graphite and pyrolytic graphite, and graphitelike boron nitride, are modeled using the parameters of Tables $\mathbf{I}-$ III and the results compared with the data reported by Marsh ${ }^{25}$ and Wackerle (Fig. 1, Figs. 6-8, and Fig. 10). In most cases, we assume the Grüneisen parameter, $\gamma$ takes a form $\gamma / \gamma_{0}=V / V_{0}$, where the subscript 0 indicates the zero-pressure value. For the case of $\alpha$ quartz to stishovite and $g-\mathrm{BN}$ to $c-\mathrm{BN}$ transformation we assume $\gamma=\gamma_{0}$ to $\mathrm{ob}-$ tain a better fit to the mixed phase data. The starting pressures at which the phase transformations begin to occur are chosen based on the Hugoniot data reported and have been adjusted to achieve an overall fit to the data.
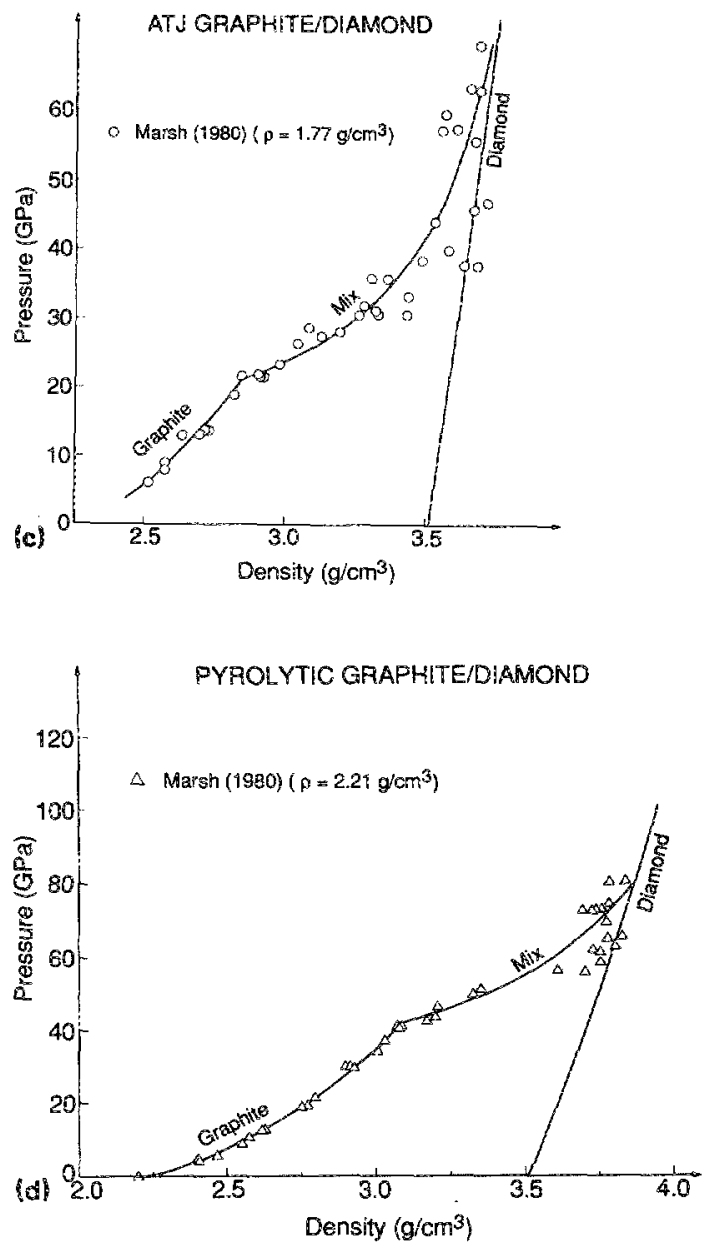

FIG. 8. Graphite to diamond transition. (a) Pressed graphite $\left(\rho_{0}=1.95 \mathrm{~g} / \mathrm{cm}^{3}\right)$. Solid line shows the results when $C_{V}=3 \mathrm{R}$ is used whereas dotted line corresponding a Debye specific heat. (b) Pressed graphite $\left(\rho_{0}=1.88 \mathrm{~g} / \mathrm{cm}^{3}\right)$. (c) ATJ graphite. (d) Pyrolytic graphite. 


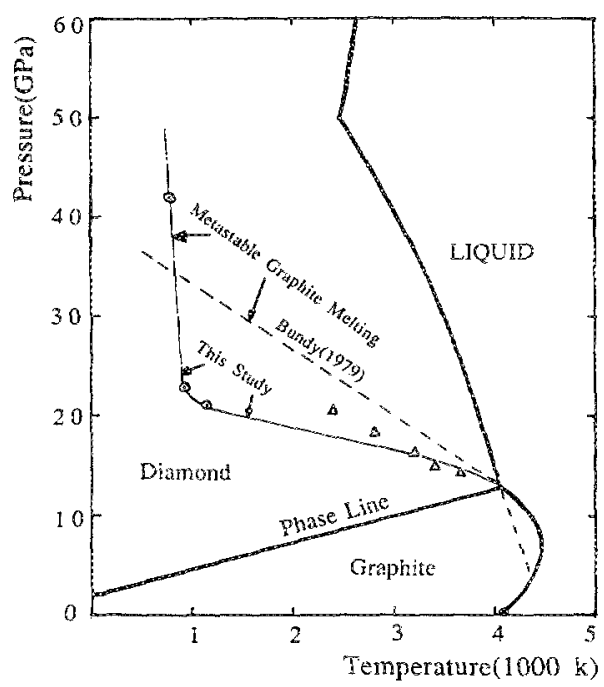

FIG. 9. Phase diagran of carbon (Bundy, see Ref. 26). Direct static graphite to diamond transition of Bundy and calculated results of this work.

The infuence of the Grineisen parameter, $\gamma$, on the calculated results for fused quartz is examined in Fig. 6. The cusp calculated at the onset of the fused quartz to stishovite transition disappears when $\gamma=\gamma_{0}$ is used instead of $\gamma / V$ $=$ const. The calculated shock temperature is greater than $3000 \mathrm{~K}$ when shock pressure is over $40 \mathrm{GPa}$. Significant shock melting of stishovite which has been transformed from fused-quartz probably occurs and may explain the relatively poor fit for the high-pressure data when $\gamma \equiv \gamma_{0}$ is used. ${ }^{22}$

A fit to the ceramic quartz is shown in Fig. 7. We treat this sample as porous $\alpha$ quartz. The poor fit in the low-pressure phase regime may result from the rigidity of the porous $\alpha$-quartz ceramic. Shock melting occurs at lower pressure in porous material than nonporous. At pressures above 30 GPa, shock temperatures are greater than $3000 \mathrm{~K}$. We can fit the data by changing the value of $\gamma_{0}$ for the high-pressure phase. In Fig. 7, we show the result for $\gamma_{0}=0.65$.

$B$ Bundy ${ }^{26}$ conducted a comprehensive study of the graphite-to-diamond phase transition occurring under different conditions. He pointed out that the direct and fast (dynamic or static) graphite to diamond transformation (without additives) might be closely related to the melting ine of the metastable graphite. His phase diagram for carbon is presented in Fig. 9. Our calculations for graphite (Fig. 8) also predict the temperature-pressure conditions along the extension of this metastable graphite melting line. States for onset of transition are $\sim 920 \mathrm{~K}$ at $23 \mathrm{GPa}$ (for pressed graphite with initial density $\left.1.95 \mathrm{~g} / \mathrm{cm}^{3}\right), \sim 800 \mathrm{~K}$ at $42 \mathrm{GPa}$ (for pyrolytic graphite of density $2.21 \mathrm{~g} / \mathrm{cm}^{3}$ ), and $\sim 1140$ Kat $21 \mathrm{GPa}$ (for ATJ graphite of initial density $1.77 \mathrm{~g} /$ $\mathrm{cm}^{3}$ ). These points are shown in Fig. 9 , resulting in a metastable melting line similar in shape to that of quartz (Fig. 5), and generally similar to that suggested by Bundy. ${ }^{26}$

The calculated result for the $g-B N / c-B N$ transformation (Fig. 10) is in good agreement with the limited Hugonlot data, taking into account the paucity of actual data for input parameters needed in the calculation (see Table $M$ II). The theoretical Hugoniot for $c-B N$ is approximated by two different data sets: one is the Hugoniot data of diamond, ${ }^{27}$ the other is the isothermal data of $c$-BN recently reported by Knittle et $a l^{28}$ Figure 10 (a) shows the result when assuming $\gamma / V=$ const with $\gamma_{0}=0.9,{ }^{27}$ whereas Fig. $10(b)$ shows $\gamma \equiv \gamma_{0}$ with $\gamma_{0}=0.6{ }^{33}$ Knittle $e t$ al. have suggested the $\gamma_{0}$ value for $c-B N$ to be 1.87 , which we find will result in a $P-V$ curve significantly above the observed data in the mixedphase region at high pressures. Although these two Hugonlot differ, the calculated $P$ - $V$ relationship in the mixed-phase region is almost the same. Since our starting $g-\mathrm{BN}$ material only has a density $2.08 \mathrm{~g} / \mathrm{cm}$, about $91 \%$ of the crystal density, we calculated the $c$-BN Hugoniot corresponding to this porous $g-\mathrm{BN}$ starting material from

$$
E_{S_{2}}(V)+\left[P-P_{S_{2}}(V)\right](V / \gamma)_{2}=E_{H}-E_{\mathrm{qr}}
$$

An interesting result from the calculation is the standard entropy value for $c-B N$ which we infer to be between 0.40 and $0.50 \mathrm{~J} / \mathrm{gK}$. Figure 10 also shows the results when the entropy value of $c-B N$ is approximated by that of diamond.
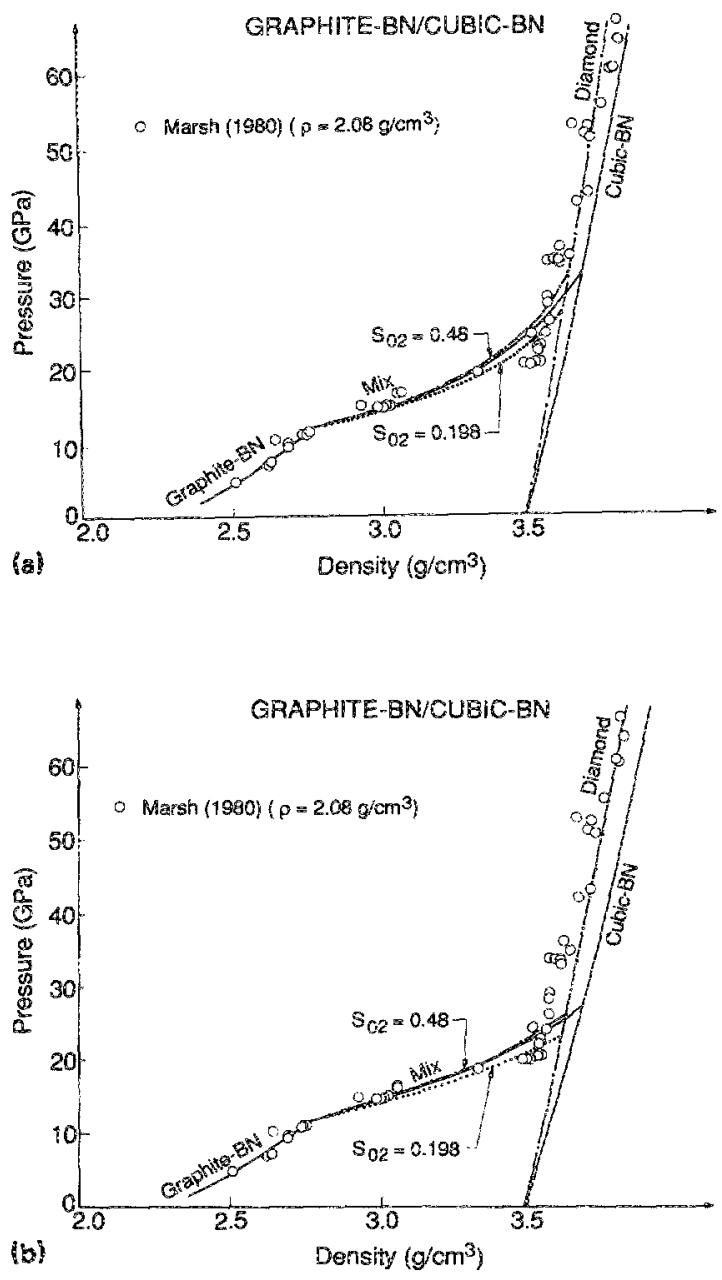

FIG. 10. Calculated and observed porous graphitelise boron nitride $(g$ $\mathrm{BN}$ ) to cubic boron nitride transformation starting at $12 \mathrm{GPa}$. Dotted line is obtained when entropy value of diamond is assumed for $c-B N$. (a) $\gamma /$ $V=$ const, $\gamma_{3}=0.9$ (diamond); (b) $\gamma=0.6=$ const. 
Note added in proof. We recently became aware that like $\mathrm{H}_{2} \mathrm{O}$ and $\mathrm{SiO}_{2}$ the low-pressure phase of $\mathrm{C}$ and graphite transforms to an amorphous material upon static compression at room temperature at $\gtrsim 20 \mathrm{GPa}[3$. Exp. Theor. Phys. 96, 670 (1989)]. This, as indicated in Fig. 9, would correspond to crossing the metastable extension of the extension of the negative sloping melting line of graphite as depicted in Fig. 9.

\section{ACKNOWLEDGRENTS}

Research supported under NASA Contract No. NGL05-002-105; Defense Nuclear Agency, Contract No. DNA001-87-C-0125; and Army Research Office Contract No. DAA-LO3-88K0199. Contribution No. 4950, Division of Geological and Planetary Sciences, California Institute of Technology, Pasadena, California.

'J. Wackerle, J. Appl. Phys. 33, 922 (1962).

${ }^{2}$ R.G. MCQueen and S. P. Marsh, Behavior of Dense Media under High Dynamic Pressures, Symposium H. D. P., Paris, September 1967 (Gordon and Breach, New York, 1968).

${ }^{3}$ G. A. Adadurov, Z. G. Aliev, and L. O. Atovmyan, Sov. Phys. Dok1. 12, $173(1967)$.

${ }^{4}$ R. G. McQueen, J. N. Fritz, and S. P. March, J. Geophys. Res. 68, 2319 (1963).

${ }^{5}$ B. V. Zamyshlyaev, E. A. Govorukha, and V. A. Shcherbatyuk, Sov. Phys. Dokl. 27, 324 (1982).

${ }^{6}$ T, J. Ahrens (Lunar \& Planetary Inst., Houston, TX, 1988).

${ }^{7}$ D. R. Schmitt and T. J. Ahrens, Geophys. Res. Lett. 10, 1077 (1983).

${ }^{8}$ D. R. Schmitt and T. J. Alurens, J. Geophys. Res. 94, 5851 (1989).

${ }^{9}$ D. E. Grady, J. Geophys. Res. 85, 913 (1980).

${ }^{10}$ E. M. Stolper and T. J. Ahrens, Geophys. Res. Lett. 14, 1231 (1987).

"S. M. Rigden, T. J. Ahrens, and E. M. Stolper, J. Geophys. Res. 93, 367 (1988).
${ }^{12} \mathrm{Q}$. Williams and R. Jeanloz, Science 239, 902 (1988).

${ }^{13}$ O. Mishima, L. D. Calvert, and E. Whalley, Nature 310, 393 (1984).

${ }^{14}$ R. J. Hemley, in Migh Pressure Kesarch in Mineral Physics, edited by M. Manghnani and $Y$. Syono (Terra Scientific, Tokyo, Japan, 1987), pp. $347-360$.

${ }^{t 5}$ R. J. Hemley, A. P. Jepheoat, H. K. Mao, M. C. Ming, and M. H. Manghnani, Nature 334, 52 (1988).

16p. S. DeCarli and J. C. Jamieson, Science 133, 1821 (1961).

${ }^{87}$ D. E. Grady, W. 1. Murri, and P. S. DeCarii, J. Geophys. Res. 80, 4857 (1975).

'P. S. DeCarli and J. C. Jamieson, J. Chem. Phys. 31, 1675 (1959).

19D. J. Milton and P. S. DeCarli, Science 140, 670 (1963).

${ }^{20}$ A. Gratz, I. Non-Cryst. Solids 67, 543 (1984).

${ }^{2}$ T. J. Ahrens and V. G. Gregson, Jr., J. Geophys. Res, 69, 4839 (1964).

${ }^{22}$ G. A. Eyzenga, T. J. Ahrens, and A. C. Mitchell, J. Geophys. Res. 88, 2431 (1983).

${ }^{23}$ T. J. Ahrens, Methods Exp. Phys. 24, Part A, 185 (1987).

${ }^{24}$ W. H. Press and B. P. Flannery, in Numerical Recipes: The Art of Scientific Computation (Cambridge University Press, New York, 1986).

${ }^{25}$ S. P. Marsh, Ed., LASL Shock Hugoniot Data (University of California, Berkeley, CA, 1980).

${ }^{26}$ F. P. Bundy, J. Geophys. Res. 85, 6930 (1980).

${ }^{27}$ M. N. Pavlovskii, Sov. Phys. Solid State 13, 741 (1971).

${ }^{28} \mathrm{E}$. Knittle, R. M. Wentzcovitch, R. Jeanloz, and M. L. Cohen, Nature 337,349 (1989).

${ }^{29}$ R. A. Robie, H. S. Hemingway, and J. R. Fisher, in Thermodynamic Properties of Minerals and Related Substances at $298.15 \mathrm{~K}$ and $1 \mathrm{Bar} 110^{5} \mathrm{Pas}-$ cals) Pressure and at High Temperatures (United States Government Printing Office, Washington, 1978).

${ }^{30}$ O. L, Anderson, E. Schreiber, and R. C. Liebermann, Rev. Geophys. 6, 491 (1968).

31. A. Dean, Ed., Lange's Handbook of Chemistry (McGraw-Hill, New York, 1985).

${ }^{32}$ M. W. Chase, Jr., C. A. Davies, J. R. Downey, Jr, D. J. Frurip, R. A. McDonald, and A. N. Syyerud, in JANAF Thermochemical Tables, 3rd ed. (Dow Chemical Co and the American Institute of Physics for the National Bureau of Standards, Miedland, MII, 1985).

${ }^{33} \mathrm{H}$. Tan and T. J. Ahrens, J. Mater. Res. 3, 1010 (1988).

${ }^{34}$ Q. Willians and R. Jeanloz, Nature 338, 413 (1989).

${ }^{35}$ D. K. Schmitt and T. J. Ahrens, Geophys. Res. Lett. 10, 1077 (1983). 